\title{
Changes in natural torsional frequency of horizontally-curved bridge by reinforcement
}

\author{
N. Kunla \& B. Puangkird* \\ Department of Mechanical Engineering, Faculty of Engineering \\ King Mongkut’s Institute of Technology Ladkrabang, Bangkok, Thailand \\ kpbumroo@kmitl.ac.th*
}

\begin{abstract}
Horizontally curved steel I-girder bridge (HCSIB) has low torsional resistance hence has a high risk of breakage when it vibrates. This study investigated the changes in the natural torsional frequency of an HCSIB when it is reinforced with different types of bracing members. Three-dimensional finite element numerical analysis with Evolution FEA opensource software was applied to an established model of HCSIB. The simulation results showed that the changes in the bridge's natural torsional frequency caused by reinforcement with $K, Z$, and $X$-type cross frames were significant and almost equal to each other, and reinforcement with extra X-type cross frames caused a bigger change, but reinforcement with bottom bracings caused a much smaller change. Overall, K-type cross frames are the best choice for reinforcement because they are the most economical while providing virtually the same high torsional frequency as those provided by the other two cross frames.
\end{abstract}

Keywords - evolution-fea; finite element; torsional vibration; natural frequency; curved steel I-girder

\section{INTRODUCTION}

Horizontal curved steel I-girder bridges (HCSIG bridge) are commonly built over highway inter-changes to meet the growing traffic capacity demand of large urban areas. They have several advantages such as reduced total construction cost and time but also have a disadvantage of low torsional stiffness.

An HCSIG bridge may flex easily by external dynamic loads such as moving vehicles and wind. Its horizontal curvature induces significant torsion in the bridge girder system, and so its natural torsional frequency needs to be carefully taken into account in a design. A research study by $\mathrm{H}$. Maneetes and D.G. Linzell [1] reported that an HCSIG bridge was prone to flexing and raising its natural torsional frequency should reduce this risk.

Typically, I-girders are connected by cross frames or bracing members of other types in order to enhance its torsional resistance and hence its strength. Research works on numerical analysis of natural frequency of curved beam and girder are such as the following. C. G. Culver and D. J. Oestel [2] developed a method for determining the natural frequency of a curved multi-span beam by combining the Rayleigh-Ritz method with Lagrange multiplier concept and used it to analyze a two-span beam. K.Y. Yoon, N.H. Park, Y.J. Choi, and Y.J. Kang [3] presented a finite element (FE) method for free vibration analysis of horizontally curved I-girder based on a previous study of Y.J. Kang and C.H. Yoo [4]. An-other FE method was proposed by B.Y. Kim, C.B. Kim, S.H. Song, H.G.
Beom, and C.D. Cho [5] for analyzing out-of-plane vibration of curved beams. A differential quadrature method for determining natural frequency was developed by K.J. Kang [6].

All of the studies described above are limited to beams with no intermediate cross frames or bottom bracings. In practice, however, beams and girders are usually connected to each other by cross frames or bracing members of other types. The following stud-ies took bracing members into consideration. $\mathrm{H}$. Maneetes, and D.G. Linzell [1] investigated the effects of X and K-type cross frames and bottom bracings on prevention of lateral displacement, reduction of dynamic stress, and inducement of change of natural frequency that, in turn, affects displacement. The authors recommended K-type cross frame over X-type one because it is more economical yet raises the natural frequency almost equally well. J.Y. Meng, and E.M. Lui [7] studied the torsional effects on a short-span highway bridge and suggested that their findings should be carefully taken into account in a seismic design of a bridge. Hence, an in-depth study of the natural torsional frequency of HCSIG bridge is well warranted.

This study focused on the changes in the natural torsional frequency of an HCSIG bridge caused by reinforcement with bracing members of different types: three types of cross frames and a type of bottom bracings. Three-dimensional FE numerical analyses of an established model of a girder bridge reinforced with each type of the bracing members mentioned were performed by using Evolution FEA software that was proven accurate in the work of N. Kunla and B. Puangkird [8] and the simulation results are presented.

\section{GIRDER GEOMETRY}

The model of the HCSIG bridge investigated in this study was developed from the data of a typical bridge of its kind reported by $H$. Maneetes and D.G. Linzell [1]. This model consists of three simply sup-ported I-girders reinforced with a number of cross frames. Its geometry is as follows: three Igirders spaced radially at a distance of $2.67 \mathrm{~m}$; radii of curvature of the outside girder (G3) of $63.63 \mathrm{~m}$, of the middle girder (G2) of $60.96 \mathrm{~m}$, and of the inside girder (G1) of 58.29 $\mathrm{m}$; and spans along their arc length of G1, G2, and G3 of 26.2, 27.4, and $28.6 \mathrm{~m}$, respectively. The dimensions of the webs and the flanges of the girder are shown in Fig. 1, while the dimensions of the cross frames and bottom bracings are shown in Table I. In addition, illustrations of the 3 types of cross frames and the bottom bracing are shown in Fig. 6 and 7, 
respectively, and a plan view of the curved I-girders is shown in Fig. 2.

TABLE I. DIMENSIONS OF CROSS FRAME AND BOTTOM BRACING

\begin{tabular}{lccc}
\hline \multirow{2}{*}{ Bracing Member } & Diameter & & Thickness \\
\cline { 2 - 2 } & $\mathrm{mm}$ & $\mathrm{mm}$ \\
\hline Cross frame & 127 & 6.4 \\
\hline Bottom Bracing & 127 & 6.4 \\
\hline
\end{tabular}

Flange $508 \mathrm{~mm} \times 30 \mathrm{~mm}$

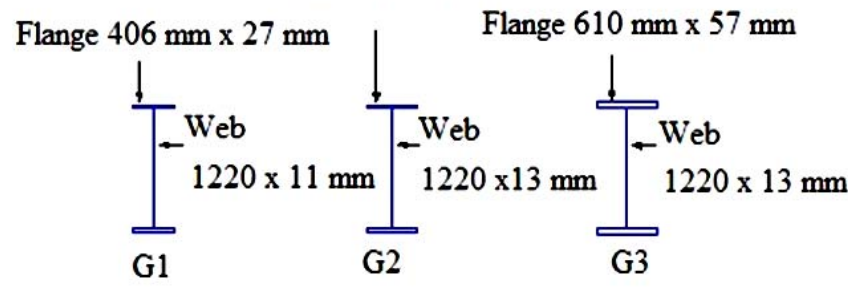

Fig. 1. Girder cross section

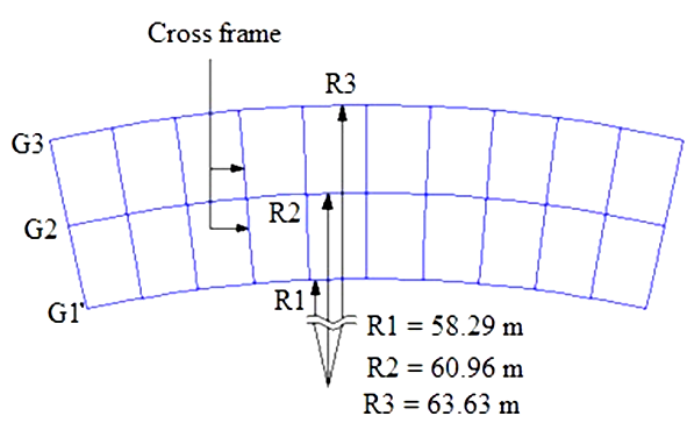

Fig. 2. Plan view of girder geometry

\section{FINITE ELEMENT MODEL}

In this study, a finite element (FE) program called Evolution FEA was used for FE analyses. To verify its validity, it was used to analyze data presented in the following 3 studies-a study by N. Photong and K. Tangchaichit [9], by K.Y. Yoon, N.H. Park, Y.J. Choi and Y.J. Kang [3] and by H. Maneetes and D.G. Linzell [1]-and the simulation results were compared. It was found that the results obtained from the opensource Evolution FEA differed from those obtained from different commercial software programs employed in those studies by less than $2 \%$. This finding indicated that Evolution FEA was accurate enough to be used for this study.

Details and settings of this study's FE model of girders and bracing members are given in the 4 sub-sections below.

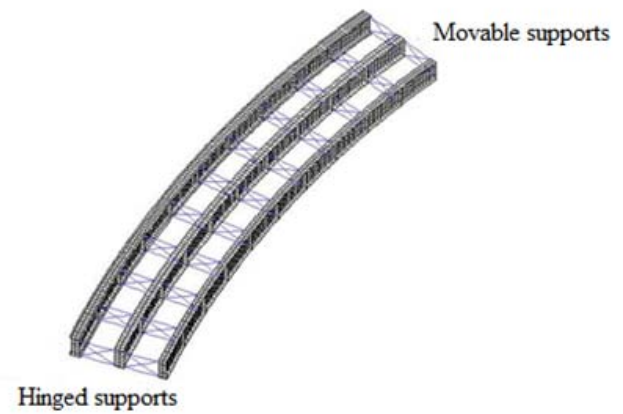

Fig. 3. Curved I-girders and their boundary

\section{A. Boundary Conditions}

Regarding their boundary conditions, the girders had a hinged support at one end and a movable support at the other end, as shown in Fig. 3. The types of boundary conditions with respect to displacements and rotations about the global $\mathrm{x}, \mathrm{y}$ and $\mathrm{z}$ axes $-u, v, w, \theta_{1}, \theta_{2}$ and $\theta_{3}$-are listed in Table II.

TABLE II. BOUNDARY CONDITIONS

\begin{tabular}{lcccccc}
\hline Type & $u$ & $v$ & $w$ & $\theta_{1}$ & $\theta_{2}$ & $\theta_{3}$ \\
\hline $\begin{array}{l}\text { Hinged } \\
\text { Movable }\end{array}$ & Fix & Fix & Fix & Free & Free & Free \\
\hline & Fix & Fix & Free & Free & Free & Free \\
\hline & & & & Note $: u, v, w$ are translation in the $\mathrm{x}, \mathrm{y}, \mathrm{z}$ directions \\
$\theta_{1,}, \theta_{2}, \theta_{3}$ are rotations about $\mathrm{x}, \mathrm{y}, \mathrm{z}$ directions
\end{tabular}

\section{B. Mesh Model}

Md. R. Awall, T. Hayashikawa, T. Matsumoto, and X. He. [10] used shell elements to model flanges, webs, and transverse web stiffeners in their simulation of natural torsional frequency, and the results were proven to be very accurate when compared to the real, measured values. This kind of accuracy was also confirmed in an investigation by N. Kunla, and B. Puangkird [8]. Therefore, three-dimensional (3D) four-node shell elements (S4R5) were employed to model the same structural elements in this study. However, cross frames and bottom bracings were modeled with B31 beam elements as done in the work of H. Maneetes, and D.G. Linzell [1] because his works on bridges have been widely cited. Each S4R5 element had four integration points across it and five section points through its thickness, while each B31 element had two nodes, each with six degrees of freedom (DOF).

Based on the dimensions and mechanical properties of the model bridge investigated in the work by H. Maneetes and D.G. Linzell [1], the bridge model simulated in this study was constructed of approximately 6,300 elements and 33,000 DOF. In order to validate this model, the first mode of natural lateral vibrational frequency, shown in Fig. 4, obtained from this model's FE analysis was compared to the measured value reported in the work by H. Maneetes and D.G. Linzell [1], and they were found to be different by only less than $2 \%$. Therefore, a mesh with the said numbers of elements and DOFs was considered adequate for this study. Fig. 5 shows a 3-D view of the mesh model without any bottom bracings. 


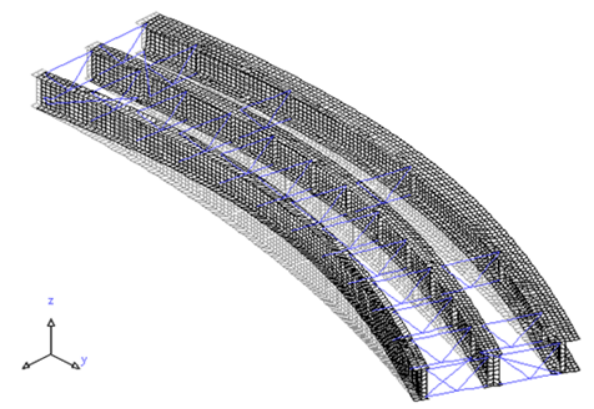

Frequency found by FE analysis of this model $=2.94 \mathrm{~Hz}$ Measured frequency reported in CSBRP $=2.90 \mathrm{~Hz}$

Fig. 4. The first mode of lateral

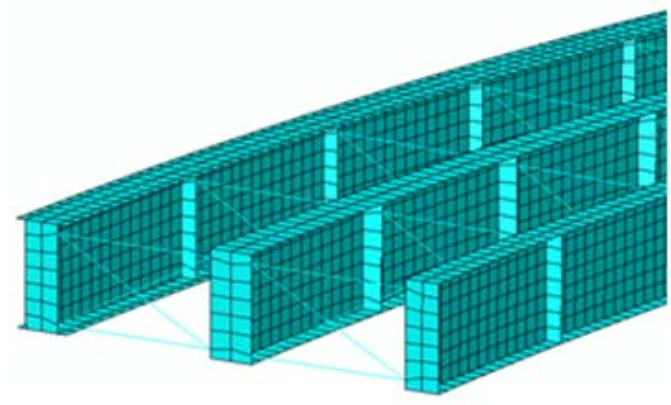

Fig. 5. The mesh model

\section{Mechanical Properties of Girder, Cross Frame, and Bottom Bracing}

Construction materials of the girders, cross frames, and bottom bracings in this model were assumed to be homogenous, isotropic, and in compliance with Hook's law. Their mechanical properties are described in Table III.

TABLE III. MECHANICAL PROPERTIES OF MATERIALS

\begin{tabular}{|c|c|c|c|c|}
\hline \multirow[t]{2}{*}{ Model part } & \multirow[t]{2}{*}{ Material } & \multirow{2}{*}{$\begin{array}{l}\text { Density } \\
\text { Kg/m3 }\end{array}$} & \multirow{2}{*}{$\begin{array}{c}\begin{array}{c}\text { Young's } \\
\text { modulus }\end{array} \\
\mathrm{GPa}\end{array}$} & \multirow{2}{*}{$\begin{array}{c}\text { Poisson's } \\
\text { ratio }\end{array}$} \\
\hline & & & & \\
\hline Girder & $\begin{array}{l}\text { Carbon } \\
\text { steel }\end{array}$ & 7850 & 200.0 & 0.3 \\
\hline $\begin{array}{l}\text { Cross } \\
\text { frame }\end{array}$ & $\begin{array}{l}\text { High } \\
\text { strength } \\
\text { steel }\end{array}$ & 7850 & 0.503 & 0.3 \\
\hline $\begin{array}{l}\text { Bottom } \\
\text { bracing }\end{array}$ & $\begin{array}{l}\text { High } \\
\text { strength } \\
\text { steel }\end{array}$ & 7850 & 0.503 & 0.3 \\
\hline
\end{tabular}

\section{FE Analysis}

FE analyses by Evolution FEA were performed to determine the natural torsional frequencies of the model bridge reinforced with different types of bracing members. The analyses were done in 2 steps: first, finding the natural torsional frequency with Fourier analysis; and second, finding a consistent mode shape according to modal assurance criterion [11] to validate the frequency found in the first step.

FE analyses were performed with cross frames of each type, with a number of extra cross frames (a plan view of the bridge with extra cross frames is shown in Fig. 13) and with bottom bracings or without bottom bracings, as shown in Fig. 6 and Fig. 7.

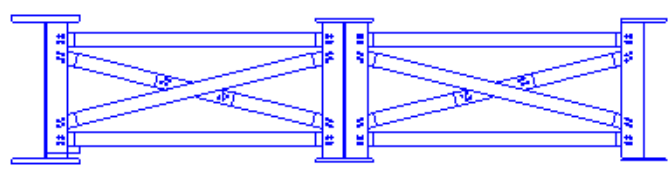

X-type

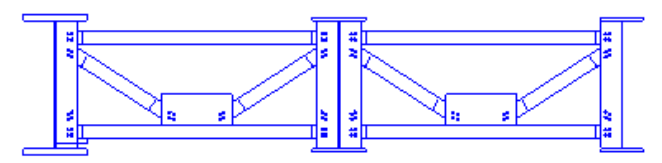

K-type

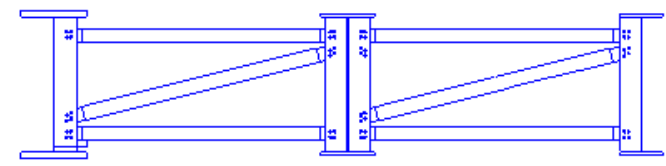

Z-type

Fig. 6. Types of cross frame

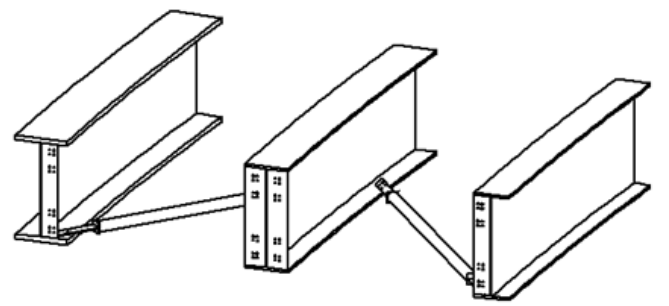

Fig. 7. Bottom bracings

\section{RESUlts}

The effects of reinforcement with different types of cross frames and bottom bracings on the natural torsional frequency of our model bridge are presented below.

\section{A. Effects of reinforcement with different types of cross frames}

Illustrations of our model bridge, reinforced with cross frames of each of the three types and without any bottom bracings, vibrating in the first torsional mode are shown in Fig. 8 to Fig. 10. Their natural torsional frequencies, which were almost equal, are listed in Table IV. 


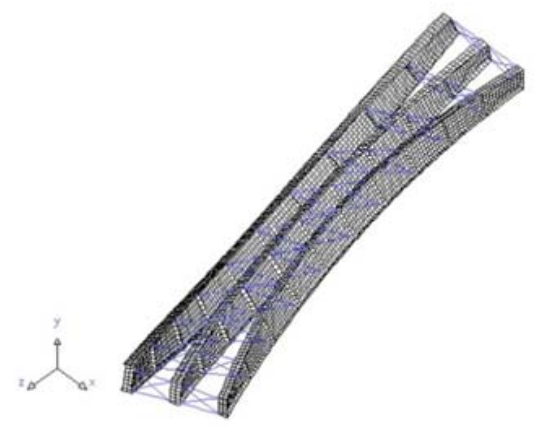

FE analysis: $4.04 \mathrm{~Hz}$

Fig. 8. 1st torsional mode of curved steel I-girder built with X-type cross frames

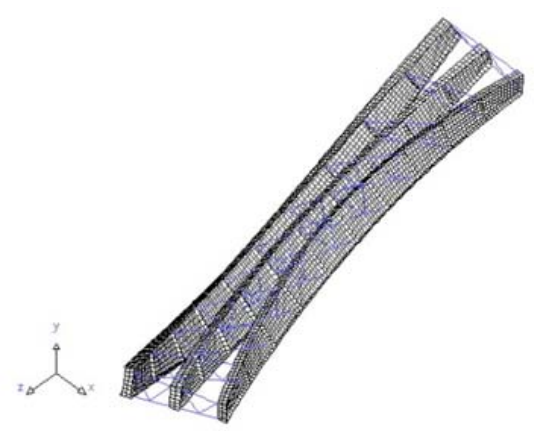

FE analysis: $3.99 \mathrm{~Hz}$

Fig. 9. 1st torsional mode of curved steel I-girder built with K-type cross frames

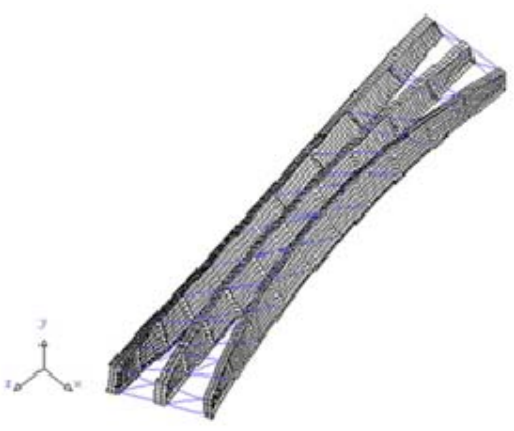

FE analysis: $3.98 \mathrm{~Hz}$

Fig. 10. 1st torsional mode of curved steel I-girder built with Z-type cross frames

TABLE IV. NATURAL FREQUENCIES FOR THE FIRST TORSIONAL MODE OF I-GIRDERS BUILT WITH DIFFERENT TYPES OF CROSS FRAMES

\begin{tabular}{lcccc}
\hline Mode & \multicolumn{3}{c}{ Natural frequencies of girder composed } \\
\cline { 2 - 3 } & $\begin{array}{c}\text { X-type } \\
\text { cross frame }\end{array}$ & & $\begin{array}{c}\text { K-type cross } \\
\text { frame }\end{array}$ & $\begin{array}{c}\text { Z-type } \\
\text { cross frame }\end{array}$ \\
\cline { 2 - 3 } & $\mathrm{Hz}$ & & $\mathrm{Hz}$ & $\mathrm{Hz}$ \\
\hline $1^{\text {st }}$ Torsional & 4.04 & & 3.99 & 3.98 \\
\hline
\end{tabular}

\section{B. Effects of reinforcement with different types of cross frames}

An illustration of the girder system reinforced with X-type cross frames and added bottom bracings is shown in Fig. 11. The natural frequencies of the first torsional mode of the girder system with and without the bottom bracings are given in table $\mathrm{V}$, and the mode shape of the former is shown in Fig. 12.

After the girder system was additionally reinforced with bottom bracings, its torsional frequency increased by only $1 \%$. This increment is too small to warrant using them to improve a bridge's resistance to torsional vibration.

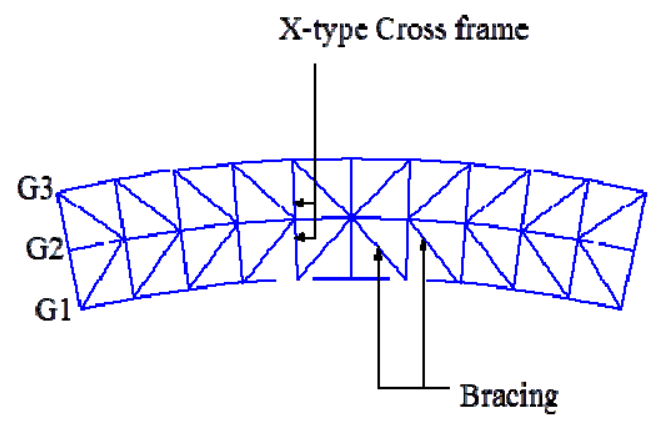

Fig. 11. I-girder system with bottom bracings

TABLE V. NATURAL FrequenCIES OF The First TORSIONAL MODE OF THE I-GIRDER SYSTEM MODEL WITH AND WITHOUT BOTTOM BRACINGS

\begin{tabular}{|c|c|c|}
\hline \multirow[t]{3}{*}{ Mode } & \multicolumn{2}{|c|}{ Natural frequencies } \\
\hline & $\begin{array}{c}\text { Without additional } \\
\text { bottom bracing }\end{array}$ & $\begin{array}{c}\text { With additional bottom } \\
\text { bracing }\end{array}$ \\
\hline & $\mathrm{Hz}$ & $\mathrm{Hz}$ \\
\hline $1^{\text {st }}$ Torsional & 4.04 & 4.08 \\
\hline
\end{tabular}

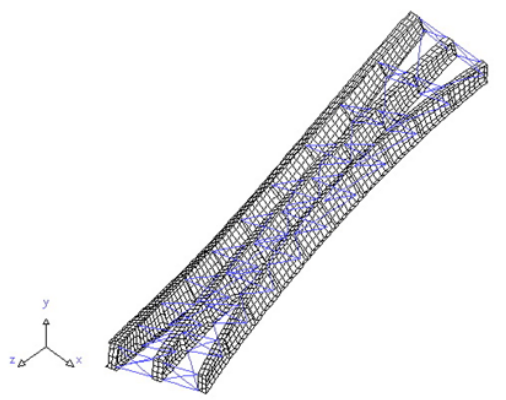

Fig. 12. 1st torsional mode for curved steel I-girder system built with bottom bracings

\section{Effect of reinforcement with extra cross frames}

Two pairs of extra X-type cross frames were added to the original model that already had 11 pairs, as illustrated in Fig. 13. The natural frequencies of the first torsional mode of the original model and the one with extra cross frames are given in table VI, and the mode shape of the latter is shown in Fig. 14. 


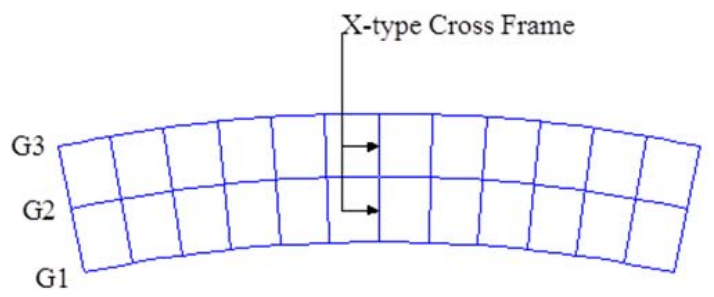

Fig. 13. Curved I-girders with extra cross frames

TABLE VI. NATURAL FrequenCIES OF THE FIRST TORSIONAL MODE OF CURVED I-GIRDERS WITH AND WITHOUT EXTRA CROSS FRAMES

\begin{tabular}{lcccc}
\hline Mode & \multicolumn{3}{c}{ Natural frequencies of girder composed } \\
\cline { 2 - 4 } & $\begin{array}{c}\text { X-type } \\
\text { cross frame }\end{array}$ & & $\begin{array}{c}\text { K-type cross } \\
\text { frame }\end{array}$ & $\begin{array}{c}\text { Z-type } \\
\text { cross frame }\end{array}$ \\
\cline { 2 - 3 } & $\mathrm{Hz}$ & & $\mathrm{Hz}$ & $\mathrm{Hz}$ \\
\hline $1^{\text {st }}$ Torsional & 4.04 & & 3.99 & 3.98 \\
\hline
\end{tabular}

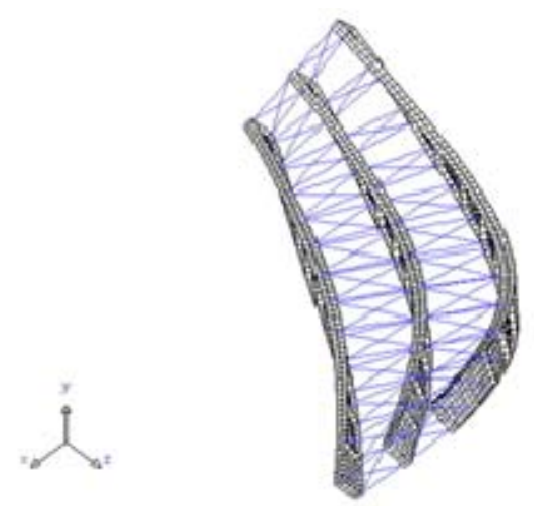

Fig. 14. 1st torsional mode of curved steel I-girders with extra cross

The higher torsional frequency of the girder sys-tem with extra cross frames was likely the results of the extra weight and stiffness, as similarly pointed out by, H, Maneetes and D.G. Linzell [1]. The girder system built with extra X-type cross frames exhibited a 10\%-higher natural torsional frequency than the one built without. This increased natural frequency was $7.8 \%$ higher than that of the system reinforced instead with bottom bracings of the same weight, showing that reinforcing the system with extra cross frames gave it more resistance to torsional vibration than doing so with bottom bracings.

\section{CONCLUDING REMARKS}

This paper numerically investigated the effects of cross frames and bottom bracings on the natural torsional frequency of a computer model of a horizontally curved steel I-girder bridge based on an established bridge investigated in a work of H. Maneetes and D.G. Linzell [1]. Three-dimensional FE analyses were performed with Evolution FEA open-source software. Numerical results indicated that the girder system reinforced with cross frames of any of the three types investigated (X-type, K-type and Z- type) exhibited almost the same natural torsional frequencies. However, adding bottom bracings to the girder system resulted in only $1 \%$ increase in the natural torsional frequency, whereas adding extra X-type cross frames of the same weight resulted in a significantly higher increase. Hence, we concluded that adding cross frames and bottom bracings does indeed increase the natural torsional frequency of a horizontally curved steel I-girder bridge. Moreover, similar to a recommendation by $\mathrm{H}$. Maneetes and D.G. Linzell [1], we suggest K-type cross frames as the best choice for reinforcing an HCSIG bridge because they strengthen the bridge as effectively as those of the other types but are much more economical.

\section{REFERENCES}

[1] H. Maneetes and D.G. Linzell, "Cross- Frame and lateral bracing influence on curved steel bridge free vibration response”, J. Const. Steel Res. vol. 59, pp. 1101-1117, 2003.

[2] C.G. Culver and D.J. Oestel, "Natural frequencies of multispan curved beams”, J. Sound Vib. vol. 10, no. 3, pp. 380-389, 2000.

[3] K.Y. Yoon, N.H. Park, Y.J. Choi and Y.J. Kang, "Natural frequencies of thin-walled curved beams”, Finite Elements in Anal. Des. vol. 42, pp. 1176-1186, 2006.

[4] Y.J. Kang and C.H. Yoo, "Thin-walled curved beams, II: analytical solutions for buckling of arches”, J. Eng. Mech ASCE vol. 120, no. 10, pp. 2102-2125, 1994.

[5] B.Y. Kim, C.B. Kim, S.H. Song, H.G. Beom and C.D. Cho, “A finite thin circular beam element for out-of-plane vibration analysis of curved beams”, J. Mech. Sci. Technol. vol. 23, pp. 1396-1405, 2000.

[6] K.J. Kang, "Vibration Analysis of Thin-walled Curved Beams using DQM”, J. Mech. Sci. Technol. vol. 21, pp. 1207-1217, 2007.

[7] J.Y. Meng, and E.M. Lui, "Torsional effects on the vibration of thinwalled beams”,Comput. Struct. vol. 75, no. 6, pp. 619-629, 2000.

[8] N. Kunla and B. Puangkird, "Effect of cross frame and bottom bracing on torsional nature frequency of horizontally curved steel I-girder", Proceedings of The 19th International Annual Symposium on Computational Science and Engineering, pp. 21-30, 2015.

[9] N. Photong and K. Tangchaichit, "Transition from Plate-Like to beamLike behavior of Cantilevered Plates and Beams”, The 20th Conference of the Mechanical Engineering Network of Thailand:AMM 044, 2006.

[10] Md. R. Awall, T. Hayashikawa, T. Matsumoto and X.W. He, “ Effects of bottom bracings on torsional dynamic characteristics of horizontally curved twin I-girder bridges with different curvatures”, Earthq. Eng. Eng. Vib. vol. 11, pp. 149-162, 2012.

[11] M. Pastora, M. Bindaa and T. HarparikaKang, "Modal assurance criterion”, Proceedia Engineering. vol. 48, pp. 543-548, 2012. 